\title{
Low head hydropower - its design and economic potential
}

\author{
Jana Hadler ${ }^{1, *}$, Klaus Broekel ${ }^{1}$ \\ ${ }^{1}$ University of Rostock, Institute of Engineering Design, Rostock, Germany \\ * Corresponding author. Tel: +49 381 4989181, Fax: +49 381 4989172, E-mail: jana.hadler@uni-rostock.de
}

\begin{abstract}
The large scale model of a Free Stream Energy Converter (FSEC) is built, and can be installed in protected as well as in tidal areas. This is one of the determined objectives of the EU-Project HYLOW, funded by the FP7. First field tests with rope winch and towing boat were done; further, in a protected area near Rostock, and the installation in the River Ems under tidal conditions and ship traffic, are planned for the first half of 2011. Besides, the permanent design control for the FSEC is as necessary as the monitoring of the behaviour of the model positioned in all the sites. If design changes or modifications are necessary, these can be done directly on site, respectively in the Steel Construction Company nearby. Whether it is suited for practice, however, is still dependent on other factors. The investigations are primarily limited on technical and ecological level. It is now necessary to look at the cost-sided development, too. Starting with considerations for the financing and economic efficiencies about expressive cost-benefit analyses up to design and material costs, the European need should be determined in hydropower for low potentials. Realization of hydropower plans takes a long period.
\end{abstract}

Keywords: Low head differences, Free Stream Energy Converter, EU-Project, Hylow, Cost-benefit analysis.

\section{Introduction}

One reason for the Hylow project is the rising demand for energy. Another one is the necessity to implement renewable energies, because of undeniable importance in view of declining natural resources. Small hydropower is a possible substitute for fossil fuels which are already limited. The European committee has fixed specific targets with a view to initiating change towards renewable energy. In order to achieve these objectives, energy generating systems, which were economically unattractive, are given greater priority.

The Hylow project focuses on the development of a mobile energy converter for low head differences - a topic which is usually neglected, because of missing significant results.

\section{Motivation for hydropower}

Compared to wind power and photovoltaic, small hydropower is often undervalued - at least in the public perception. In theory the worldwide demand for energy could be covered by hydropower. But it will not be economically practical, because of the uneven distribution of water resources on world territory.

\subsection{Strong arguments}

The power source "hydropower" offers many advantages.

Minimal emissions occur just in the installation period and in the first running period, when converters have to be stabled. A running energy converter does not need a great number of additional materials or energy. In sum there are low $\mathrm{CO}_{2}$ emissions during operating time.

Hydropower requires no primary energy - therewith the respective countries relieve their own energy bills as well as they increase the security of energy supply. Furthermore, hydropower depends neither on the natural rhythm of the sun nor on the strength of the wind. This allows a permanent and continuous electricity generation. 
There is a significant potential for hydropower in the EU and worldwide. However, the availability of use is limited by specific features of energy supply, such as localization, use of sites, power supply and current collection.

\subsection{Background of Hylow}

Small hydropower plants are close to nature; their design is often environmentally compatible. This applies to Hylow also. The floating Large Scale Model (LSM) of the FSEC is nearly $7,800 \mathrm{~mm}$ in length, $2,400 \mathrm{~mm}$ in width, and 3,500 $\mathrm{mm}$ in height. The wheel diameter is $3,200 \mathrm{~mm}$ and $1,100 \mathrm{~mm}$ in width (see Figure 1).

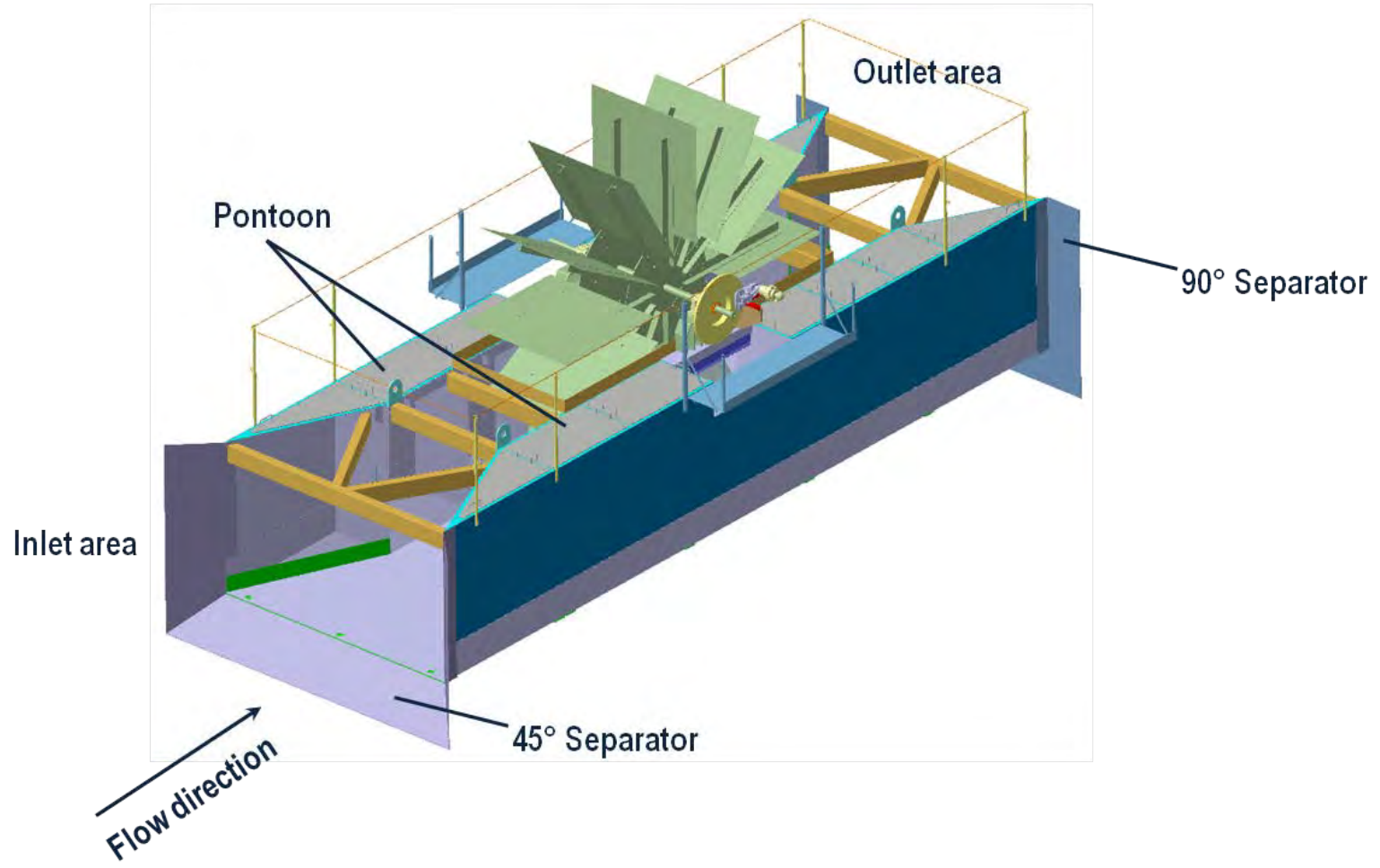

Fig. 1. The CAD model of the LSM, separators included.

The LSM will be placed in running waters with flow velocities of up to $1.5 \mathrm{~m} / \mathrm{s}$. The model is dimensioned for exceptional situations, in which the velocity rises, such as floodwaters or strong winds. To realize test runs with the LSM in protected areas no lubricants or other persistent products will be used. The power take-off is envisaged as a friction-type brake, and works without any liquids, so that even in the average case the environment takes no damage. For later applications and for deployment in developing countries to energy production, the brake system will be substituted with a generator solution which is adapted in ecological respects. [1]

\section{Product development}

Essential for product development activities, besides the idea, are calculations. These start with the power output to be expected. In addition, all forces, which appear, are to be taken into consideration.

\subsection{Free Stream Energy Converter}

The first geometry of the pontoon was given by calculations and basis tests done with simplified and down scaled configurations. The outline geometry consists of two hulls which 
are connected via a base. The hulls in the inlet area are v-shaped, so that the channel will get narrowed, and the flow velocity accelerates. This procedure corresponds to the Venturi principle. [1]

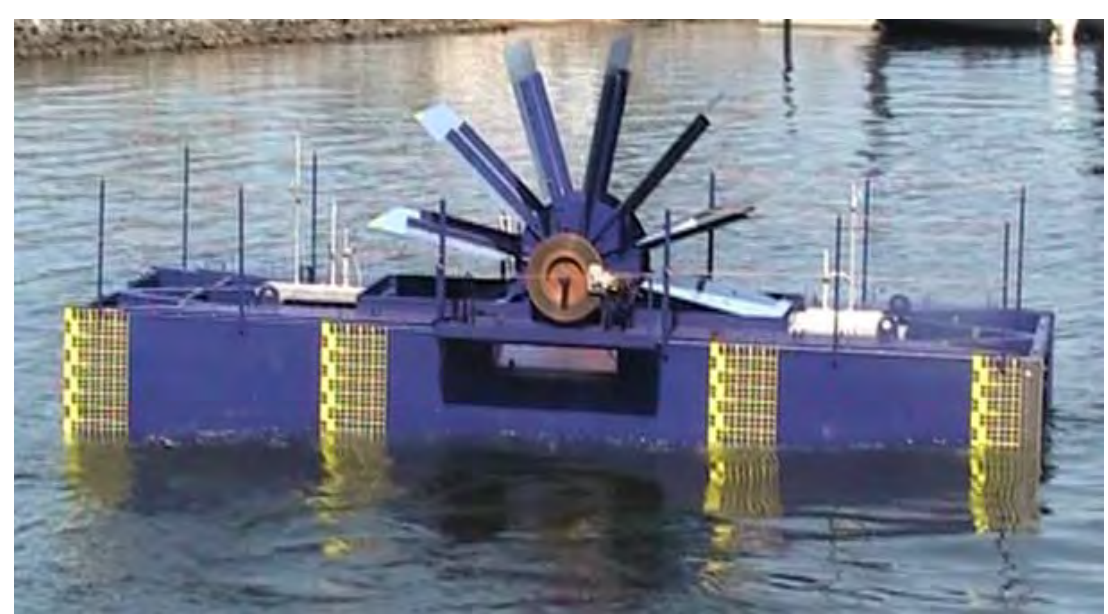

Fig. 2. The LSM on the first deployment - the naval base in Rostock.

During the whole project three field tests with the LSM at different locations (with expected flow velocities between 0.4 and $1.5 \mathrm{~m} / \mathrm{s}$ ) are planned. The first deployment site was envisaged for towing tests; these tests have been successfully completed in autumn, 2010 (see Figure 2). The second and third test sites are in a protected area near Rostock, and in the River Ems in Northern Germany.

Initial towing tests were meant to demonstrate the model behaviour during operational conditions. In addition, the floating behaviour of the model with different velocities and geometries (additional separators) should be tested. The LSM delivered an electric power output up to $500 \mathrm{~W}$.

The towing tests show that something has to be changed concerning the geometry of the LSM. The best results in the first deployment site were achieved with separators at both ends of the LSM. In the inlet area works the separator as a scoop with an angle of $45^{\circ}$, and in the outlet it has $90^{\circ}$. In order to limit the costs several models have to be analysed with the computational fluid dynamics (CFD) software FLOW-3D [3]. See first results in Figure 3.

The FLOW-3D tests are useful for the fine adjustment of length, arrangement and angular size of the separators. Moreover, the trim angle of the FSEC can be adjusted according to the waterline (horizontal alignment in the flow). Figure 3 shows three situations in FLOW-3D with different arrangements of the separators. The set velocity is determined with $1 \mathrm{~m} / \mathrm{s}$, and it changes as expected in several areas of the flow pattern - in narrowed parts of the channel are higher velocities than in the widened areas. The simulations are ongoing; final results are expected in spring, 2011. 

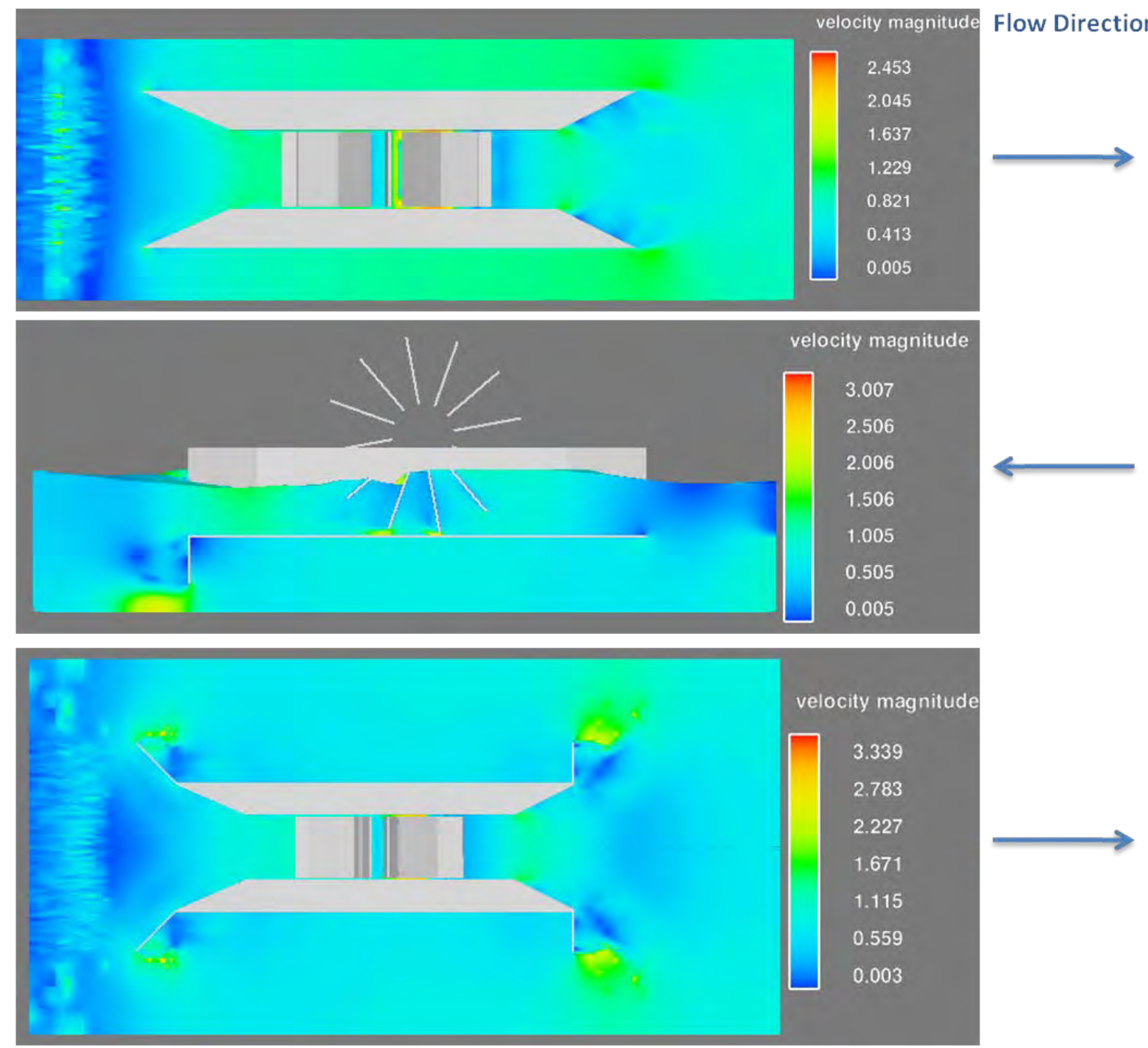

Fig. 3. Geometry tests with FLOW-3D.

\subsection{Cost report of the FSEC prototype}

To check the efficiency of the FSEC the annual costs are compared with the benefit. The benefit will be calculated from the sale of electricity to the energy companies. Thus, the investment can determine the annual profit, as the difference between the yields and costs. For the considerations, the average values of all costs and yields are used.

The total costs of the energy converter arise from different cost types. A calculation basis of these are the given production costs of the prototype which consist as follows (table 1):

Table 1. Production costs for prototype.

\begin{tabular}{cc}
\hline Cost type & Total $[€]$ \\
\hline Personnel costs & $30,491.00$ \\
\hline Material, standard parts \& consumables & $24,750.00$ \\
Indirect costs (20 \% of direct costs) & $11,048.20$ \\
\hline Manufacturing costs & $66,289.20$ \\
\hline
\end{tabular}

In these costs no costs for research and development included. Because of the prototype, no values of experience have still integrated into the production procedure. Moreover, detailed 
values of wear behaviour are neglected, because there are no empirical values for this special case exist.

\section{An FSEC in Europe - where conditions are most favorable}

The benefit of the FSEC consists in the production of electrical energy using the potential of flowing water. For the feed in existing electrical grids there are fixed feed-in tariffs which mostly have a limited duration. In addition, a purchase obligation by the energy groups exists in several European countries.

\subsection{Feed-in tariffs}

Table 2 shows height and duration of the feed-in tariffs for selected European countries. To calculate the annual yield the payment must be multiplied by the energy generated in the year. It is assumed that the FSEC works continually without interruption 8,760 hours per year. The electrical energy is the product of the expected average electric power (assumption $=3 \mathrm{~kW}$ ) and the annual power consumption in hours.

In case of permanent consumption the electrical energy for $3 \mathrm{~kW}$ power output will be $26,280 \mathrm{kWh}$. The resulting annual yields are given in the right column of table 2 [3]. The countries are sorted according to the amount of feed-in tariffs, starting with the highest.

Table 2. Feed-in tariffs and their time limits in Europe.

\begin{tabular}{cccc}
\hline European country & $\begin{array}{c}\text { Amount of } \\
\text { feed-in tariff }\end{array}$ & $\begin{array}{c}\text { Duration of } \\
\text { feed-in tariff* }\end{array}$ & Annual yield \\
\hline [€/kWh] & {$[$ years] } & {$[€]$} \\
\hline Great Britain & 0.23 & - & 6044.40 \\
\hline Italy & 0.22 & 15 & 5781.60 \\
\hline Germany & 0.1267 & 20 & 3329.68 \\
\hline Netherlands & 0.125 & 15 & 3285.00 \\
\hline Latvia & 0.11 & 10 & 2890.80 \\
\hline Slovenia & 0.105 & 15 & 2759.40 \\
\hline Czechia & 0.081 & 30 & 2128.68 \\
\hline Denmark & 0.0803 & 10 & 2110.28 \\
\hline Luxembourg & 0.079 & 15 & 2076.12 \\
\hline Spain & 0.077 & 25 & 2023.56 \\
\hline Portugal & 0.075 & 20 & 1971.00 \\
\hline Ireland & 0.072 & 15 & 1892.16 \\
\hline Greece & 0.07 & 10 & 1839.60 \\
\hline Lithuania & 0.07 & - & 1839.60 \\
\hline Slovakia & 0.066 & 15 & 1734.48 \\
\hline France & 0.06 & 20 & 1576.80 \\
\hline Estonia & 0.051 & 12 & 1340.28 \\
\hline Belgium & 0.05 & - & 1314.00 \\
\hline Bulgaria & 0.045 & 15 & 1182.60 \\
\hline Austria & 0.0378 & 13 & 993.38 \\
\hline Hungary & 0.029 & payoff time & 762.12 \\
\hline$*$ Sola & & \\
\hline
\end{tabular}

* Some values are not known; duration is unlimited. 
The European countries of the first rows have a good chance to invest in the small hydropower market. Therefore the use of the energy converter is determined as a value size. Now as a comparison the costs are considered.

\subsection{Overview to cost covering}

Thus, the production costs fall with renewed individual manufacture on $70 \%$, because the development is concluded and is possible for a shorter manufacturing time by experienceguided, structured work.

With a small batch production of five energy converters, a cost reduction on 60\% (according to the manufacturer) is to be achieved. With these estimates the manufacturing costs change as follows (table 3):

Table 3. Types of production series.

\begin{tabular}{cc}
\hline Manufacturing costs for & Price per unit $[€]$ \\
\hline Prototype & $66,289.20$ \\
Individual production & $46,402.44$ \\
Batch production (5 pieces) & $39,773.52$ \\
\hline
\end{tabular}

It is assumed that steady wear behaviour during utilisation exists. The amount of annual depreciation may be calculated according to the linear method. Thereby in every period the same depreciations are created. If the lifespan is 20 years, than the following results can be represented (table 4):

Table 4. Cost structure for all considered production series.

\begin{tabular}{|c|c|c|c|}
\hline & $\begin{array}{c}\text { Prototype } \\
100 \% \\
\end{array}$ & $\begin{array}{c}\text { Individual } \\
\text { production } \\
70 \% \\
\end{array}$ & $\begin{array}{c}\text { Small batch } \\
\text { production } \\
60 \% \\
\end{array}$ \\
\hline & {$[€]$} & {$[€]$} & {$[€]$} \\
\hline Personnel costs & $30,491.00$ & & \\
\hline Direct costs & $24,750.00$ & & \\
\hline Indirect costs & $11,048.20$ & & \\
\hline Total manufacturing costs* & $66,289.20$ & $46,402.44$ & $39,773.52$ \\
\hline Imputed depreciations** & $3,314.46$ & $2,320,12$ & $1,988.68$ \\
\hline Imputed interests*** & $1,756.66$ & $1,229.66$ & $1,054.00$ \\
\hline Imputed costs of capital & $5,071.12$ & $3,549.78$ & $3,042.68$ \\
\hline Leasing costs & 200.00 & 200.00 & 200.00 \\
\hline Maintenance costs & 253.56 & 177.49 & 152.13 \\
\hline Insurance, taxes, administration & 530.31 & 371.22 & 318.19 \\
\hline Annual costs & $6,054.99$ & $4,298.49$ & $3,713.00$ \\
\hline
\end{tabular}


The imputed costs of capital are divided into imputed depreciation and imputed interests. The imputed depreciations are the costs for losses in value. Whereas the imputed interests are the interests due on the amount of money lent over the maturity of the operation period.

The amount of the leasing costs depends on the plant size and the location. It varies from country to country, therefore it was assumed that the leasing costs are $200 €$ per year (average value in Germany). The maintenance costs are $5 \%$ of the imputed costs of the capital. The costs for insurance, taxes and administration are $0.8 \%$ of the total manufacturing costs.

Concluding, the following table 5 gives an overview to the first five European countries and the profit per annum (annual yield minus costs).

Table 5. Profit per annum for all considered production series.

\begin{tabular}{cccc}
\hline European country & $\begin{array}{c}\text { Prototype } \\
\mathbf{1 0 0 \%}\end{array}$ & $\begin{array}{c}\text { Individual } \\
\text { production }\end{array}$ & $\begin{array}{c}\text { Small batch } \\
\text { production }\end{array}$ \\
\hline & {$[€]$} & {$[€]$} & {$[€]$} \\
\hline Great Britain & -10.59 & $1,745.91$ & $2,331.40$ \\
Italy & -273.39 & $1,483.11$ & $2,068.60$ \\
Germany & $-2,725.31$ & -968.81 & -383.32 \\
Netherlands & $-2,769.99$ & $-1,013.49$ & -428.00 \\
\hline Latvia & $-3,164.19$ & $-1,407.69$ & -822.20 \\
\hline
\end{tabular}

The profit table clearly shows that the prototype is not profitable in the next 20 years. With the other production forms the FSEC under described conditions could be a lucrative business.

\section{Summary}

The FSEC is able to convert the kinetic energy of flowing waters into electricity. By means of low head differences and by applications of separators power outputs of at least $3 \mathrm{~kW}$ are expected. To attain this objective a lot of additional research is needed. Initial results of the ongoing FLOW-3D trials show how the design of the FSEC might essentially change.

The presented cost report demonstrates that only in a few European countries the balance between annual costs and benefit can be achieved. The most important criterion is how long the payback period is. The other item to note is that all the assumptions are defined as cases with ideal conditions. It is still uncertain how long an FSEC in this form will work.

In the manufacture of the FSEC prototype, personnel and material costs is the biggest cost block by far. As a result of batch production and growing experience the personnel costs will be reduced. It is to think about moving the production of further plants in countries which have lower production costs to cover the risk of rising material costs, because of the development in the steel market. It is expected that the steel price and in this connection the material costs for the converter will increase. The saving in materials has direct impacts on the operating earnings, especially when using alternative materials such as wood or glass fibre plastics (GRP) [2]. 


\section{Acknowledgements}

The research leading to these results has received funding from the European Community's Seventh Framework Programme [FP7/2007-2013] under grant agreement nº 212423.

\section{References}

[1] J. Hadler and K. Broekel, (2010), Development and design of low potential hydropower converters in protected areas, in Proceedings of hidroenergia 2010, Lausanne, June 16 19, 2010.

[2] J. Hadler and K. Broekel, (2011), Cost-benefit analysis for low potential hydropower converters, in Proceedings of $34^{\text {th }}$ IAHR World Congress 2011, Brisbane, June 26 July 1, 2011 (not yet published).

[3] http://www.energy.eu (20.11.2010).

[4] http://www.bundesbank.de (25.11.2010). 